\title{
The Effect of Electroless Ni Coating of SiC Particles on the Corrosion Behavior of A356 Based Squeeze Cast Composite
}

\author{
Burak Dikici1,* - Cagri Tekmen² - Mehmet Gavgali - Umit Cocen² \\ 1 Yuzuncu Yil University, Ercis Technical Vocational School of Higher Education, Turkey \\ 2 Dokuz Eylul University, Metallurgical and Materials Engineering, Turkey \\ ${ }^{3}$ Ataturk University, Department of Mechanical Engineering, Turkey
}

The corrosion behavior of electroless Ni coated SiC particle reinforced squeeze cast aluminum based composite was investigated by potentiodynamic scanning (PDS) and electrochemical impedance spectroscopy (EIS) techniques in aerated and deaerated chloride solutions. Microstructural and interfacial characterization of the composite was carried out by using an optical microscope, scanning electron microscope (SEM), energy dispersion spectroscopy (EDS) and X-ray diffractometer (XRD). It has been observed that electroless $\mathrm{Ni}$ coating of SiC particles is not an effective method to improve its corrosion resistance in structural applications containing halide solution.

(C)2011 Journal of Mechanical Engineering. All rights reserved.

Keywords: electroless nickel, metal matrix composite, corrosion, EIS

\section{INTRODUCTION}

Properties of metal matrix composites (MMCs) strongly depend on the interfacial phenomena between the metal matrix and ceramic reinforcement [1] to [4]. The wettability of reinforcement by liquid metal is the key factor to achieve high interface bonding strength [5] to [7]. Unfortunately, the wettability of $\mathrm{SiC}$ particle reinforcement with molten aluminum matrix is generally poor. However, several methods including the modification of the matrix composition, coating of the reinforcement and control of process parameters have been widely used to improve the interfacial properties [8] to [11]. Among these methods, electroless nickel (EN) coating of the reinforcement, which is a simple, low-cost and an easy to use process, has been successfully applied to prevent undesired interfacial reactions and promote the wettability through increasing the overall surface energy of the reinforcement [12] to [14].

The corrosion properties of aluminum based metal matrix composites reinforced with coated ceramic particles is still in the investigation stage. In addition, the published literature on the corrosion behavior of aluminum based composites is rather limited and often contradictory [15] and [16]. The reason is generally related to the quantity of alloying elements in the $\mathrm{Al}$ matrix, reinforcement shape, size and volume fraction and composite production method [17] and [18]. Also, many researchers reported that galvanic actions between the uncoated $\mathrm{SiC}$ particle and matrix alloy is not effective in the corrosion behavior of the composite due to a semiconductor structure of $\mathrm{SiC}$ phase. In other words, $\mathrm{SiC}$ is cathodic to aluminum and does not polarize easily [19] to [21]. However, the corrosion susceptibility of the composite increases due to the presence of $\mathrm{Al}_{4} \mathrm{C}_{3}$ phase, which forms at the $\mathrm{SiC} / \mathrm{Al}$ matrix interface [17], [22] and [23]. $\mathrm{Al}_{4} \mathrm{C}_{3}$ reduces not only the corrosion resistance but also the ductility and strength of the composite [24] and [25]. Similar results have been observed in our previous studies [26] and [27]. Coating of the reinforcement changes the physical and mechanical properties of the composites, as well as the corrosion behavior [16] and [18]. Also, surface treatment of $\mathrm{SiC}$ reinforcement may improve the wetting behavior with Al matrix. However, the protective film on the matrix surface can be easily broken due to a mismatch in coefficient of thermal expansion (CTE) between different phases. In addition, corrosion can decrease the interfacial strength between SiC and Al matrix [20], [28] and [29]. Recently, a considerable attention has been paid especially to the use of these composites in marine applications [30]. However, several drawbacks of these materials, such as low temperature ductility and poor corrosion resistance hinder their wide range of application in alkaline environments [8]. 
In this study, corrosion behavior of $\mathrm{Al}-7 \% \mathrm{Si}-0.7 \% \mathrm{Mg}$ (A356) based metal matrix composite reinforced with electroless nickel (EN) coated $\mathrm{SiC}$ particles produced by squeeze casting technique has been investigated. Another purpose of this study was to increase wettability between matrix/reinforcing phase and preventing undesirable interface reactions. The coating morphology, microstructural and interfacial properties of the composite, and the effect of EN coating of $\mathrm{SiC}$ reinforcement on the corrosion properties has been examined and discussed in detail.

\section{EXPERIMENTAL PROCEDURE}

\subsection{Electroless Nickel (EN) Coating}

Electroless nickel coating of $\mathrm{SiC}$ particles was carried out as follows: cleaning of $\mathrm{SiC}$ particles in acetone for $15 \mathrm{~min}$. After cleaning, particles were sensitized for another 15 minutes in a solution containing $10 \mathrm{~g} / \mathrm{L} \mathrm{SnCl}_{2}$ and $30 \mathrm{~mL}$ $\mathrm{HCl}$. The sensitized particles were immersed in a solution containing $0.25 \mathrm{~g} / \mathrm{L} \mathrm{PdCl}_{2}$ and $3 \mathrm{ml} / \mathrm{L}$ $\mathrm{HCl}$ for $15 \mathrm{~min}$ in order to activate the nonmetal $\mathrm{SiC}$ particle surface. Rinsed and dried $\mathrm{SiC}$ particles were gently dispersed in an electroless nickel bath containing $45 \mathrm{~g} \mathrm{NiCl}_{2}, 8 \mathrm{~g} \mathrm{NaH}_{2} \mathrm{PO}_{2}$. $\mathrm{H}_{2} \mathrm{O}, 100 \mathrm{~g} \mathrm{Na}_{3} \mathrm{C}_{6} \mathrm{H}_{5} \mathrm{O}_{7}$ and $50 \mathrm{~g} \mathrm{NH}_{4} \mathrm{Cl}$ dissolved in $1 \mathrm{~L}$ distilled water. Deposition was carried out at 80 to $90{ }^{\circ} \mathrm{C}$ and 8 to $9 \mathrm{pH}$.

\subsection{Composite Manufacturing}

A composite reinforced with 20 vol. \% electroless nickel coated $\mathrm{SiC}$ particles with an average size of $15 \mu \mathrm{m}$ was produced by a squeeze casting technique. $\mathrm{Al}-7 \% \mathrm{Si}-0.7 \% \mathrm{Mg}$ matrix alloy was melted in a ceramic crucible and then $\mathrm{SiC}$ particles were added by stirring continuously. The mixture was superheated up to $750{ }^{\circ} \mathrm{C}$ and then poured into a preheated $\left(400{ }^{\circ} \mathrm{C}\right)$ die and finally solidified under a pressure of $100 \mathrm{MPa}$.

\subsection{Characterization}

Characterization studies were carried out by using optical microscope, scanning electron microscope (SEM), energy dispersion spectrometer (EDS) and X-ray diffractometer (XRD).

\subsection{Corrosion Tests}

Electrochemical investigation of the composite was performed with potentiodynamic polarization (PDS) and electrochemical impedance spectroscopy (EIS). All experiments were carried out with a computer-controlled potentiostat (PCI4/750, GAMRY Instruments, Inc., Warminster, PA) in aerated and deaerated $3.5 \% \mathrm{NaCl}$ solution at room temperature. $\mathrm{Ag} /$ $\mathrm{AgCl}$ and platinum (Pt) electrodes were used as a reference and auxiliary electrode, respectively. The solution was deaerated in order to remove the oxygen with nitrogen $\left(\mathrm{N}_{2}\right)$ gas. Deaerated process was started 60 minutes prior the measurement and continued until the end of the experiment. Specimens were immersed into the solution until obtaining a steady open circuit potential (OCP). After reaching equilibrium, polarization test started at the cathodic overpotential and the scan was stopped when the specimens reached the anodic corrosion current density of $10 \mathrm{~mA} \cdot \mathrm{cm}^{-2}$. All potentiodynamic scanning (PDS) tests were carried out according to the ASTM standard [31]. EIS measurements were carried out using AC signals of amplitude $10 \mathrm{mV}$ at the open circuit potential (OCP) in the frequency range of 100000 to $0.01 \mathrm{~Hz}$. The exposed area of the test specimens was about $5 \times 5 \mathrm{~mm}( \pm 0.01)$, and all data have been normalized according to the surface area. Impedance parameters were calculated by fitting the experimental results to an equivalent circuit model by using the Echem Analyst software.

\section{RESULTS}

\subsection{Characterization}

Surface and elemental $\mathrm{Ni}$ mapping of electroless nickel coated $\mathrm{SiC}$ particles are given in Figs. 1a and b, respectively. It has been observed that the EN coating is homogenous, uniform and the thickness is about $1 \mu \mathrm{m}$. A typical microstructure of the composite produced by squeeze casting is shown in Fig. 2. In our previous study [32], it was demonstrated that the microstructure consists mainly from aluminum 
dendrites and eutectic silicon with no evidence of macro-pores. The amount of micro-pores was measured as $0.54 \%$ (in vol.).

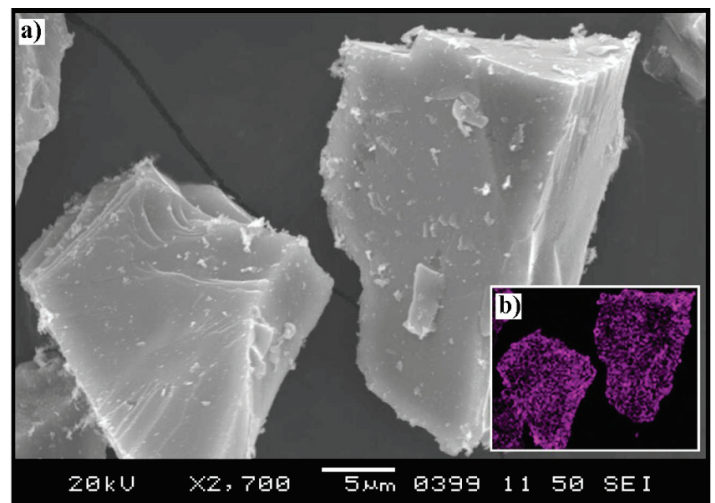

Fig. 1. a) SEM image and b) X-ray map of $\mathrm{Ni}$ on the $\mathrm{SiC}$ particle surface

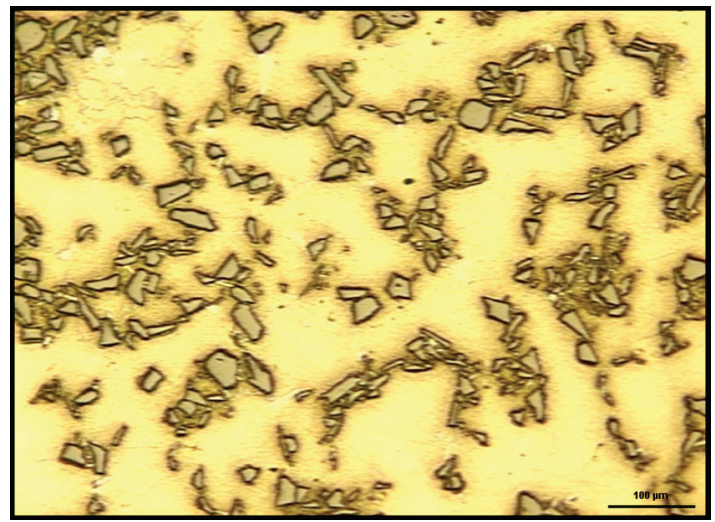

Fig. 2. Optical micrograph of squeeze cast composite

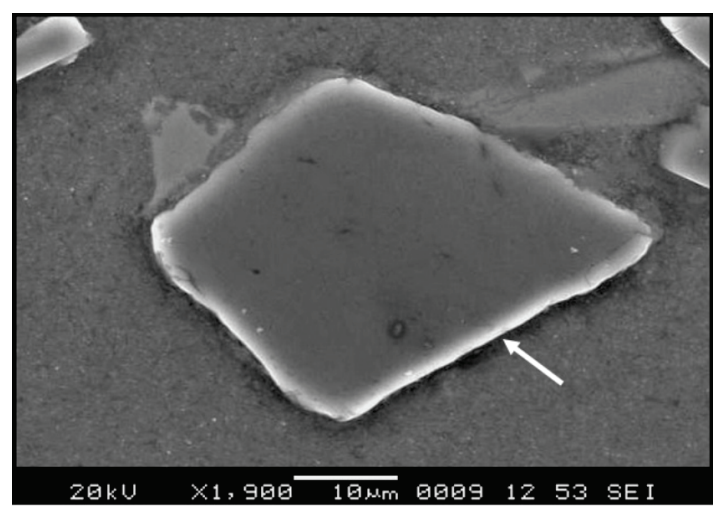

Fig. 3. SEM micrograph showing the SiC/matrix interface
Higher magnification micrograph of the composite demonstrates a good $\mathrm{SiC} /$ matrix interface in terms of porosity (Fig. 3). In addition, XRD pattern of the composite indicates that Al4C3 reaction product does not occur (Fig. 4).

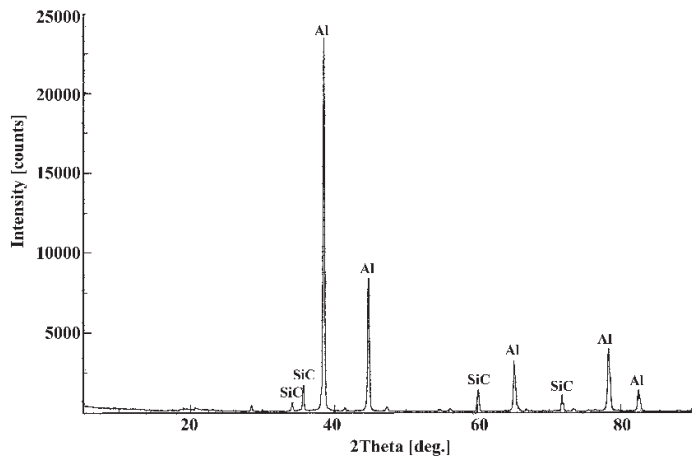

Fig. 4. XRD pattern of squeeze cast composite

\subsection{Corrosion Tests}
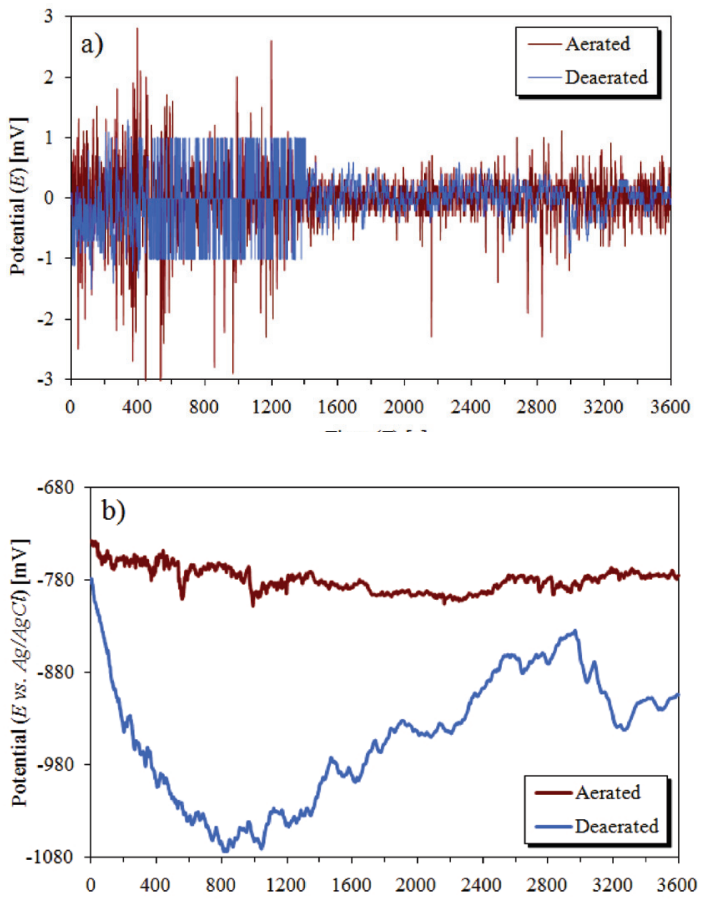

Fig. 5. a) open circuit potential-time $\left(E_{\text {ocp }}-T\right)$ curves, b) electrochemical potential noise measurements in aerated and deaerated 3.5\% $\mathrm{NaCl}$ solutions 
Open circuit potential (OCP) and electrochemical noise measurements of the composite in aerated and deaerated $3.5 \% \mathrm{NaCl}$ solutions measured against time are given in Fig. 5 . Noise values were calculated from the variation between two potential values obtained from OCP.

It is well known that a corrosion reaction may be masked by the heavily reduction reactions in aerated solution. Thus, especially aluminum alloys, pitting onset, passive areas and subtle polarization effects can not be seen completely. Therefore, the solution was deaerated to remove the oxygen by introducing nitrogen into the system. Fig. 6 shows a typical potentiodynamic polarization curve of the composite obtained in aerated and deaerated $3.5 \% \mathrm{NaCl}$ solutions. Corrosion parameters obtained from these polarization curves are collected in Table 1 .

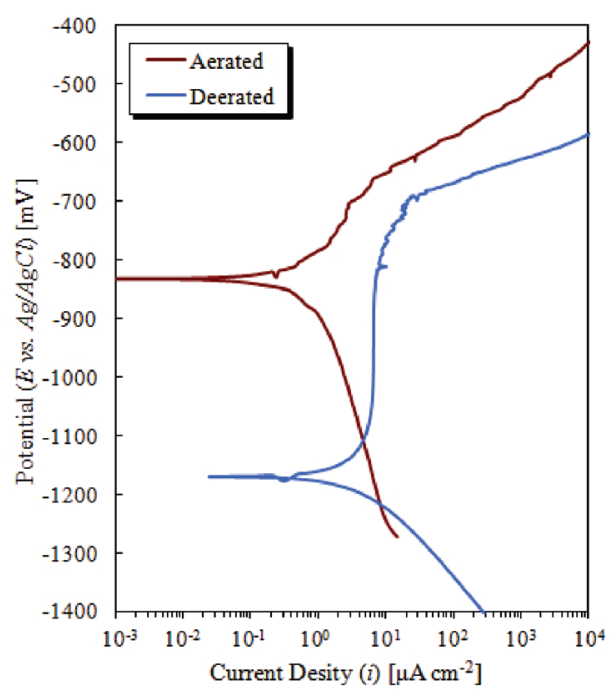

Fig. 6. Potentiodynamic polarization curves in aerated and deaerated $3.5 \% \mathrm{NaCl}$ solutions

Fig. 7 shows the impedance response of the composite in a Nyquist representation. In addition, the corrosion behavior of the composite is further illustrated by Bode plots in Fig. 8.

In order to obtain accurate results, complex plane plots were analyzed by fitting the experimental results to the equivalent circuit as given in Fig. 9. It is obvious from Fig. 7 that fitted results present a similar shape with experimental results. Also, impedance parameters derived from complex plane plots are given in Table 2 .

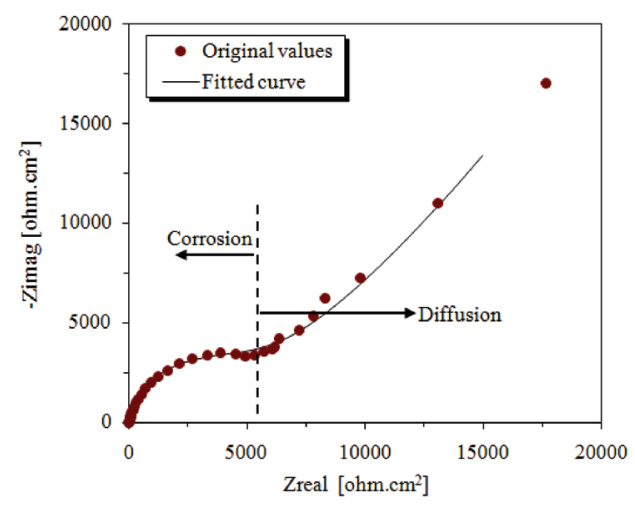

Fig. 7. Nyquist diagram of the sample exposed to aerated $3.5 \% \mathrm{NaCl}$
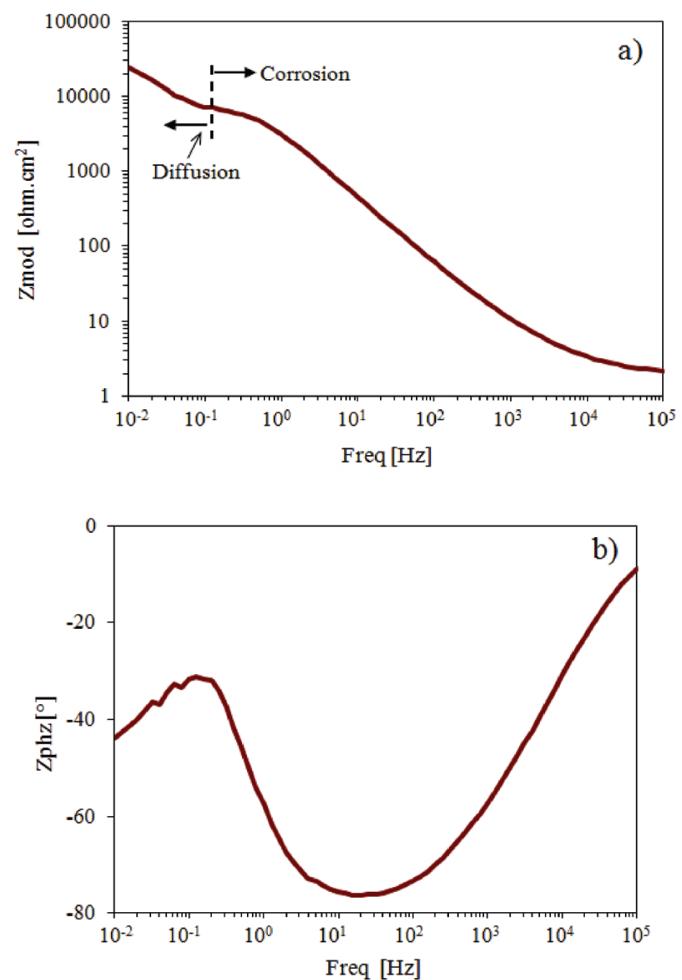

Fig. 8. Bode plots of the sample exposed to aerated 3.5\% NaCl: a) magnitude, b) phase angle

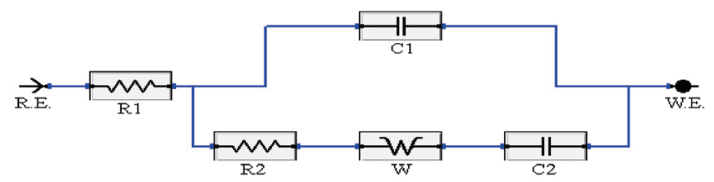

Fig. 9. Equivalent circuit model represents the metal/solution interface 
Table 1. Corrosion parameters obtained from polarization curves of the composite in aerated and deaerated $3.5 \% \mathrm{NaCl}$ solutions ( $\mathrm{Evs} . \mathrm{Ag} / \mathrm{AgCl}$ )

\begin{tabular}{|c|c|c|c|c|c|c|}
\hline Test condition & $E_{\text {ocp }}[\mathrm{mV}]$ & $E_{\text {corr }}[\mathrm{mV}]$ & $E_{\text {pit }}[\mathrm{mV}]$ & $E_{\text {pass }}[\mathrm{mV}]$ & $I_{\text {pass }}\left[\mu \mathrm{A} / \mathrm{cm}^{2}\right]$ & $I_{\text {corr }}\left[\mu \mathrm{A} / \mathrm{cm}^{2}\right]$ \\
\hline Aerated solution & -776 & -833 & -696 & - & - & 1.25 \\
\hline Deaerated solution & -904 & -1169 & -718 & -1135 & 6.15 & 2.50 \\
\hline
\end{tabular}

Table 2. Impedance parameters derived from complex plane plot in aerated $3.5 \% \mathrm{NaCl}$ solution

\begin{tabular}{|c|c|c|c|c|}
\hline$R 1\left[\Omega . \mathrm{cm}^{2}\right]$ & $R 2\left[\Omega . \mathrm{cm}^{2}\right]$ & $C 1\left(\mathrm{x} 10^{-6}\right)\left[\mathrm{F}^{\left.-\mathrm{cm}^{-2}\right]}\right.$ & $C 2\left(\mathrm{x} 10^{-3}\right)\left[\mathrm{F}^{\left.-\mathrm{cm}^{-2}\right]}\right.$ & $W\left(\mathrm{x} 10^{-6}\right)\left[\mathrm{S}^{1} \mathrm{~s}^{1 / 2} \cdot \mathrm{cm}^{-2}\right]$ \\
\hline 10.65 & 4850 & 30.33 & 6.862 & 258.6 \\
\hline
\end{tabular}

\subsection{Corrosion Morphology}

Fig. 10 is a typical SEM micrograph of a squeeze cast composite exposed to $3.5 \% \mathrm{NaCl}$ solution, where the presence of preferentially localized corrosion can be seen at $\mathrm{SiC} /$ matrix interface.
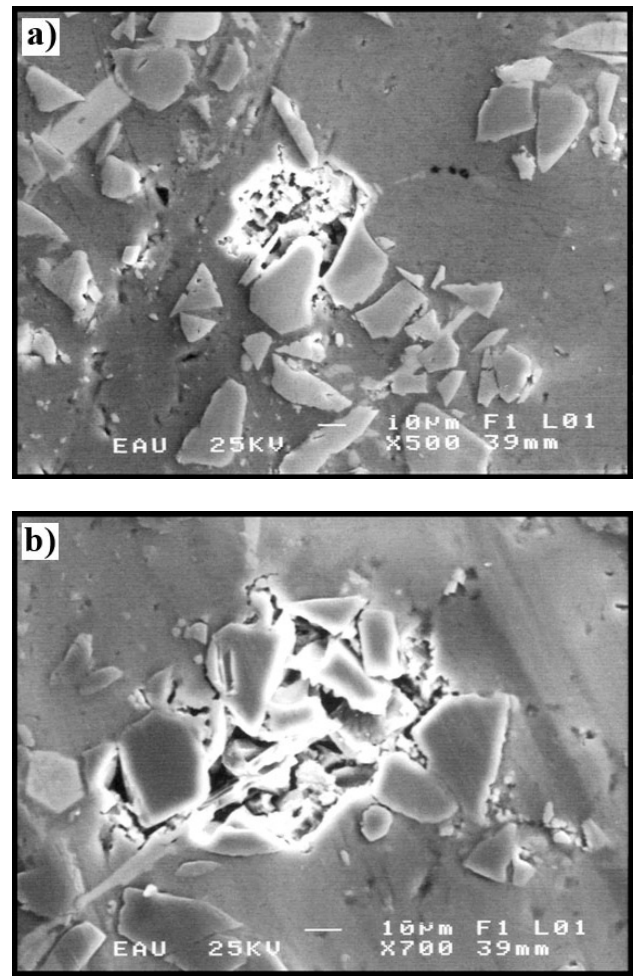

Fig. 10. SEM micrographs showing the corroded surfaces of the sample

Fig. 11 shows the corrosion progress paths on the corroded surface of squeeze cast composite at the initial and intensive corrosion stages. At extensive corrosion levels, the presence of pits at the $\mathrm{SiC} /$ matrix interface can be considered as regions where $\mathrm{SiC}$ particles are partially or completely detached (Fig. 12).
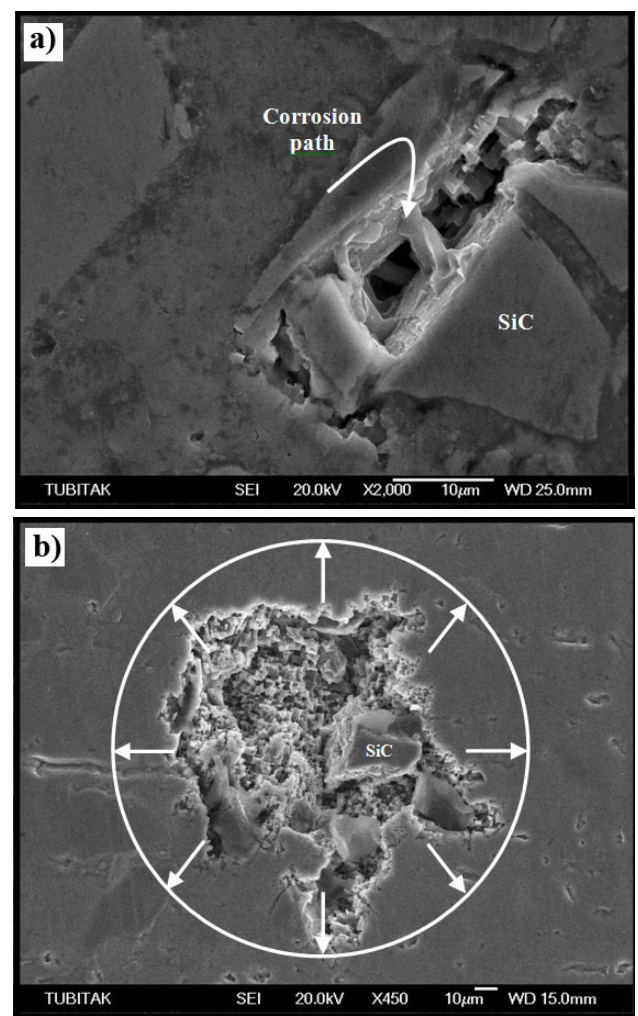

Fig. 11. Initial and intensive stages of corrosion: a) fresh pit, b) grown pit (arrow directions present corrosion paths)

Fig. 13 reveals the preferential removal of the matrix material around $\mathrm{EN}$ coated $\mathrm{SiC}$ particles. This figure illustrates that $\mathrm{SiC}$ particles are not greatly affected by the corrosion process. The corrosion progress on aluminum rich matrix, causes an intense porous structure, without any 
corrosion product on $\mathrm{SiC}$ particle surface. In addition, it was observed that corrosion did not cause any damage in the EN coating, as illustrated by small, light spheres in Fig. 13.

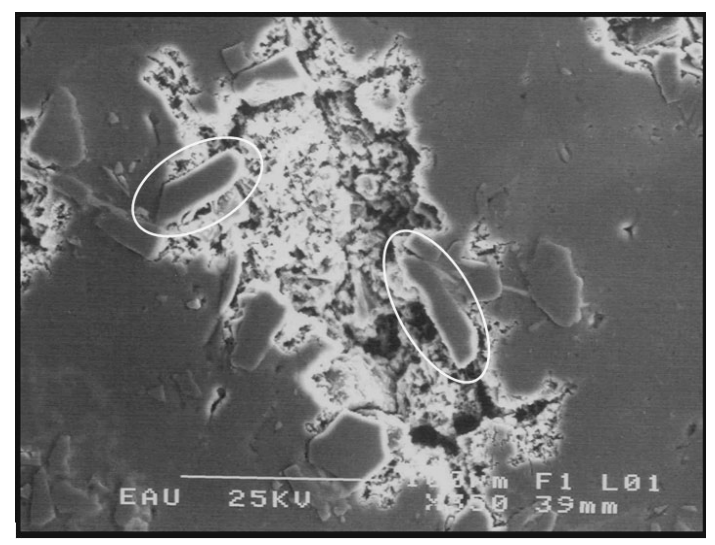

Fig. 12. Detachment of SiC particles from the structure due to intensive matrix corrosion

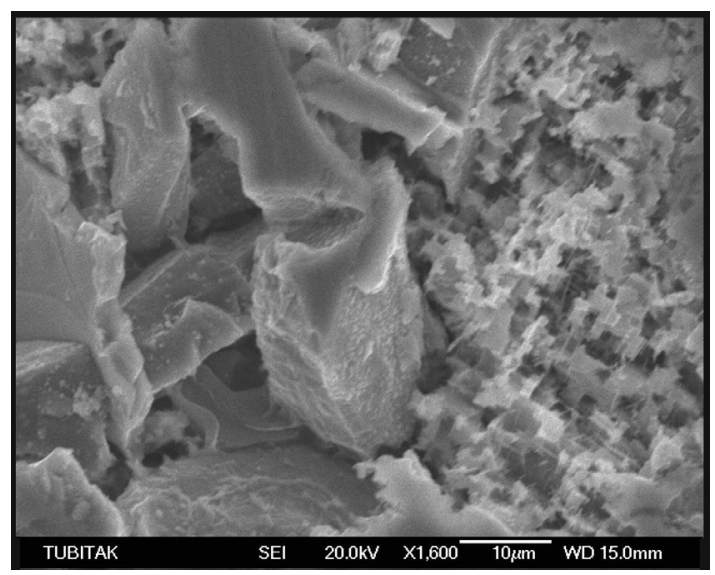

Fig. 13. High magnification SEM micrograph of EN coated SiC particles after the corrosion test

\section{DISCUSSION}

In the literature, it has been attributed that the following parameters significantly affect the corrosion behavior of metal matrix composites in macro scale; (i) reinforcement volume fraction [26] and [33], (ii) composition of the matrix alloy [28] and [34], (iii) reinforcement coating [15] and [18], (iv) composite manufacturing method [33], and (v) thermal or thermo-mechanical post treatment [33] and [35]. In addition, the corrosion principle of aluminum alloys under passive conditions establishes the pitting [19]. Therefore, for these alloys, the pitting potential value is directly related to the corrosion susceptibility, and it can provide more realistic results related to the electrochemical behavior of the composites. In spite of using the same matrix alloy and reinforcement volume fraction in this study, the corrosion and pitting results are relatively more noble (Table 1) compared to our previous study [18] and [26]. Also, since no post treatment was applied in this study, the difference in potential values cannot be explained by parameters (i), (ii) and (v) given before. Therefore, the main reason of the difference can be attributed to the manufacturing method (iv) and/or reinforcement coating (iii).

From the point of manufacturing method, in both liquid infiltration and squeeze casting methods, a composite material solidifies under pressure, therefore, its effect on microstructure, in terms of porosity and interfacial properties, is insignificant. As reported in our previous studies, the porosity ratio of $20 \%$ volume fraction $\mathrm{SiC}$ reinforced composite manufactured by liquid infiltration [18], stir casting and extrusion [20] and squeeze casting [32] is the same and approximately $1 \%$. Porosity, which acts as preferential sites for corrosion, is one of the key parameters in the corrosion behavior of composite materials. Therefore, it can be concluded that, the most effective parameter that differentiates the corrosion results obtained in each study is the type of reinforcement coating (iii).

As it is known, if the gradient of corrosion rate with time is neglible, it can be said that the material undergoes general corrosion. In such a case, it is easier to determine the corrosion rate and the lifetime of the material. However, as observed in this study, if the corrosion behavior changes significantly with time (Fig. 5), this indicates that the material undergoes pitting corrosion. In this case, the test carried out in aerated solution to determine the corrosion rate and the obtained data lose its validity and reliability, respectively [23] and [36]. In such circumstances, using the electrochemical noise technique and performing the tests in deareated solution gains importance. As seen from Fig. 5a, the open circuit potential (OCP) values of the composite measured under aerated condition are more positive than in 
deaerated condition. This can be explained by the affinity of the present and dissolved oxygen in aerated condition. The reason is that in deaerated condition, the oxygen reduction reaction given by reaction (1) will not occur, thus the growth of the surface oxide layer will be prevented. Consequently, dissolution of the metal became more dominant and the protective oxide layer became gradually thinner.

$$
1 / 2 \mathrm{O}_{2}+\mathrm{H}_{2} \mathrm{O}+2 \mathrm{e}^{-} \rightarrow 2 \mathrm{OH}^{-}
$$

In order to evaluate localized interactions, the electrochemical potential noise magnitudes of each sample were compared (Fig. 5b). 25 minutes after the sample was immersed into the electrolyte it was observed that localized corrosion is hindered due to passivation, and this inhibition is relatively stronger in deaerated solution. This can be easily seen in the magnitued graph of the noise amplitude (Fig. 5b). This result verifies that the difference in potential values observed in both studies arise from the composite structure rather than the oxidation in dilute solution.

In our previous study [18], corrosion was preferentially started and continued at the interface between the $\mathrm{Al}$ matrix and alloying elements rather than reinforcement. Also, since $\mathrm{SiC}$ particles were coated with $\mathrm{SiO}_{2}$ and $\mathrm{TiO}_{2}$, no detrimental galvanic corrosion was observed between $\mathrm{SiC}$ particles and matrix alloy. In addition, up to date, no galvanic effect has been reported between $\mathrm{Al}$ and $\mathrm{SiC}$ [28] and [33]. However, in this study, SiC particles were coated with nickel which is a relatively good conductive metal, and a metallic bond is expected to occur where $\mathrm{Al}$ and $\mathrm{Ni}$ are in direct contact. An interface with a metallic bond is more ductile than other bonds, and is desirable in metal matrix composites [8]. However, as a metallic bond has a relatively high electrical conductivity, electrons in the matrix alloy can be easily drained through the conductive EN coating in a corrosive environment,. Also, it has been demonstrated that $\mathrm{Ni}$ can react with Al matrix and intermetallic phases such as $\mathrm{NiAl}_{3}$ and $\mathrm{Al}_{3} \mathrm{Ni}_{2}$ can occur preferentially at the $\mathrm{Al} / \mathrm{SiC}$ interface [14]. These intermetallic phases frequently have solution potentials differing from that of the matrix alloy in which they occur, therefore, localized galvanic cells may be formed between these phases and the matrix. Thus, these phases are cathodic to the $\mathrm{Al}$ matrix and decrease the corrosion resistance in aqueous saline media [19] and [28].

The main effect of EN coating on the corrosion behavior of composite might be morphologic. The high pressure applied in squeeze casting might have an indirect effect on the corrosion resistance of the composite. During the solidification of composite under high pressure, some residual stresses might appear and cause an increase in the overall internal stresses in the composite. However, it has been widely accepted that these residual stresses have no or little effect on the corrosion behavior of the composite [23] and [28]. However, dislocations accumulated around $\mathrm{Al}$ dentrites and/or $\mathrm{Al} / \mathrm{SiC}$ interface can indirectly cause a degradation of the surface oxide layer, and might be effective in the change of the corrosion morphology of the composite [37] and [38]. At the advanced stage of the corrosion, if $\mathrm{SiC}$ coating is a nonconductive material, the corrosion will continue around these particles since $\mathrm{SiC}$ is a noble material and will not undergo corrosion. Thus, localized corrosion in Al matrix alloy will progress quickly and in depth, and causes less material loss. However, if the $\mathrm{SiC}$ coating is a conductive material, this increases the ratio of local cathode area around the $\mathrm{SiC}$ particle where low resistance areas exist and electrons leave easily from these areas, therefore, corrosion will progress around the $\mathrm{SiC}$ particles where the pits extend at the surface not in depth. As a result, this kind of constitutions affect the normal pitting corrosion behavior of the composite. This implies that the matrix/reinforcement interfaces are active sites for corrosion and the corrosion morphology clearly demonstrates that it progresses as pitting corrosion. The initial and intensive stages of the corrosion based on Fig. 11 where the pit morphology differs at each stage. Also, as seen from Fig. 11, corrosion starts indepth at the early stages of corrosion, and later, as a result of excessive polarization, it expanses to the surface. This can be attributed to the eutectic silicon phase, which segregates to $\mathrm{Al}$ dendrites during solidification [32] since Si decreases the solution potential of Al to more noble values [28]. Due to this fact, $\mathrm{Al}$ grain boundaries close to the $\mathrm{Al} / \mathrm{SiC}$ interface, where there are relatively active sites as a result of EN coating, will become more 
active. Consequently, these regions will become localized regions where the oxide film layer has a relatively high solubility and surface conductivity. Therefore, after corrosion propagates in-dept for a while, it will interact with these localized regions and will propagate around these regions, and will consequently spread out (Fig. 11). This progress will occur in a very short time and will continue until the reinforcement detach from the matrix (Figs. 12 and 13). This approach is well in agreement with the observation of Modi et al. [30]. As a result, this kind of constitutions may affect the normal corrosion behavior of the material.

The corrosion potential and polarization resistance during the immersion of a system in a corrosive medium can provide information regarding the ongoing corrosion reaction process. This information, as well as additional information about the solution/protection layer/composite surface interfaces can be obtained from EIS. Figs. 7 and 8 demonstrate the Nyquist and bode plots of the composite after the EIS scanning. At low frequency, the region of the Nyquist plot shows an approxinately straight line with a slope of $45^{\circ}$ (Fig. 7). In addition, the phase angle approaches $45^{\circ}$ at low frequency (Fig. 8b). In this case, it can be said that the corrosion rate is controlled by the diffusion of electrochemical active species (EAS) to the composite surface and is referred as Warburg diffusion [39]. The result confirms the Nyquist plot because Warburg Impedance appears as a straight line with a slope of $45^{\circ}$ in a Nyquist plot. Diffusion is observed at relatively low frequencies and corrosion is observed at higher frequencies (Fig. 8). This behavior demonstrates that the electron exchange between the composite and EAS is very fast. This can be attributed to a relatively high surface electrical conductivity of the $\mathrm{Al} / \mathrm{SiC}$ interface because of EN coating, which supports the above discussions. As a result, the EN surface coating method significantly affects the corrosion characteristics and the morphology of the composite.

\section{CONCLUSIONS}

In this study, it has been observed that $\mathrm{Al} /$ $\mathrm{SiC}$ interfaces are active sites where corrosion preferentially starts in-depth at the early stages, and later, as a result of excessive polarization, expanses to the surface, which indicates that the corrosion type is 'pitting'. Such corrosion behavior has been attributed to the conductivity of the coating material, eutectic silicon phase and dislocations accumulated around $\mathrm{Al}$ dendrites, by forming preferential sites for corrosion. In addition, the high pressure applied in squeeze casting might have an indirect effect on the corrosion resistance of the composite. It can be concluded that despite improving the wettability, electroless nickel coating is not an effective method to improve the corrosion resistance in structural applications containing halide solution.

\section{ACKNOWLEDGEMENTS}

This work was financially supported by Yuzuncu Yil University (2009-MYO-B031).

\section{REFERENCES}

[1] Lee, J.C., Ahn, J.P., Shim, J.H., Shi, Z., Lee, H.I. (1999). Control of the interface in $\mathrm{SiC} /$ Al composites. Scripta Mater, vol. 41, p. 895-900.

[2] Shi, Z., Yang, J.M., Fan, T., Zhang, D., Wu, R. (2000). The melt structural characteristics concerning the interfacial reaction in $\mathrm{SiC}(\mathrm{p}) /$ Al composites. Appl Phys A, vol. 71, p. 203209.

[3] Thakur, S.K., Dhindaw, B.K. (2001). The influence of interfacial characteristics between $\mathrm{SiCp}$ and $\mathrm{Mg} / \mathrm{Al}$ metal matrix on wear, coefficient of friction and microhardness. Wear, vol. 247, p. 191-201.

[4] Wang, R.M., Surappa, M.K., Tao, C.H., Li, C.Z., Yan, M.G. (1998). Microstructure and interface structure studies of SiCp-reinforced Al (6061) metal-matrix composites. Mater Sci and Eng A, vol. 254, p. 219-226.

[5] Hashim, J., Looney, L., Hashmi, M.S.J. (2001). The wettability of SiC particles by molten aluminium alloy. $J$ of Mater Proc Tech, vol. 119, p. 324-328.

[6] Hashim, J., Looney, L., Hashmi, M.S.J. (2001). The enhancement of wettability of $\mathrm{SiC}$ particles in cast aluminium matrix composites. J of Mater Proc Tech, vol. 119, 329-335. 
[7] Feng, A., McCoy, B.J., Munir, Z.A., Cagliostro, D. (1998). Wettability of transition metal oxide surfaces. Mater Sci and Eng A, vol. 252, p. 50-56.

[8] Rajan, T.P.D., Pillai, R.M., Pai, B.C. (1998). Review reinforcement coatings and interfaces in aluminum metal matrix composites. J of Mater Sci, vol. 33, p. 34913503.

[9] Rams, J., Urena, A., Campo, J. (2004). Solgel coatings as active barriers to protect ceramic reinforcement in aluminum matrix composites. Adv Eng Mater, vol. 6, p. 57-61.

[10] Wen, T., Gao, J., Shen, J., Zhou, Z. (2001). Preparation and characterization of $\mathrm{TiO}_{2}$ thin films by the sol-gel process. $J$ of Mater Sci, vol. 36, p. 5923-5926.

[11] Yang, G., Fan, T., Zhang, D. (2004). Chemical reaction in $\mathrm{Al}$ matrix composite reinforced with $\mathrm{SiC}_{\mathrm{p}}$ coated by $\mathrm{SnO}_{2} . J$ Mater Sci, vol. 39, p. 3689-3694.

[12] Libo, L., Maozhong, A., Gaohui, W. (2004). A new electroless nickel deposition technique to metallise $\mathrm{SiC}_{\mathrm{p}} / \mathrm{Al}$ composites. Surf and Coat Tech, vol. 200, p. 5102-5112.

[13] Ip, S.W., Sridhar, R., Toguri, J.M., Stephenson, T.F., Warner, A.E.M. (1998). Wettability of nickel coated graphite by aluminium. Mater Sci and Eng A, vol. 244, p. 31-38.

[14] Leon, C.A., Drew, R.A.L. (2002). The influence of nickel coating on the wettability of aluminum on ceramics. Compos A, vol. 33, p. 1429-1432.

[15] Pardo, A., Merino, M.C., Ureña, A., Merino, S., Viejo, F., Campo, M. (2004). Effect of reinforcement coating on corrosion behavior of AA6061/SiC/20 p composite in high relative humidity environments. Corrosion, vol. 60, p. 945-953.

[16] Davidson, A.M., Regener, D. (2000). A comparison of aluminium-based metalmatrix composites reinforced with coated and uncoated particulate silicon carbide. Compos Sci Technol, vol. 60, p. 865-869.

[17] Kiourtsidis, G., Skolianos, S.M. (1998). Corrosion behavior of squeeze-cast silicon carbide-2024 composites in aerated 3.5 wt.\% sodium chloride. Mater Sci and Eng A, vol. 248, p. 165-172.
[18] Dikici, B., Tekmen, C., Yigit, O., Gavgali, M., Cocen, U. (2009). Detrimental effect of particle sol-gel coating on the corrosion behavior of A380-SiC composite. Corros Sci, vol. 51, p. 469-476.

[19] Aylor, D.M., Taylor, D. (1987). Corrosion of metal matrix composites. ASM Handbook. ASM international Materials Park, vol. 13.

[20] Dikici, B., Gavgali, M., Tekmen, C. (2006). Corrosion behavior of an artificially aged (T6) Al-Si-Mg based metal matrix composite. J of Comp Mater, vol. 40, p. 1259-1269.

[21] Aylor, D.M., Moran, P.J. (1985). Effect of reinforcement on the pitting behavior of aluminum-base metal matrix composites. $J$ Electrochem Soc, vol. 132, p. 1277-1281.

[22] Yaghmaee, M.S., Kaptay, G. (2001). On the stability range of $\mathrm{SiC}$ in ternary liquid $\mathrm{Al}-\mathrm{Si}$ $\mathrm{Mg}$ alloy. In Materials Worlds: Proceeding of Hungarian Materials Science Society, vol. 2, no. 3, e-journal from http://materialworld. fw.hu.

[23] Trowsdale, A.J., Noble, B., Haris, S.J., Gibbins, I.S.R., Thompson, G.E., Wood, G.C. (1996). The influence of silicon carbide reinforcement on the pitting behaviour of aluminium. Corrosion Sci, vol. 38, p. 77191.

[24] Suery, M., Salvo, L. (1995). Matrixreinforcement interactions during fabrication and thermal treatment of cast Al-matrix composites. Metall New Mater, vol. 111, p. 119-137.

[25] Urena, A., Escalera, M.D., Rodrigo, P., Baldonedo, J.L., Gil, L. (2001). Active coatings for $\mathrm{SiC}$ particles to reduce the degradation by liquid aluminium during processing of aluminium matrix composites: study of interfacial reactions. J Microsc, vol. 201, p. 122-136.

[26] Gavgali, M., Dikici, B., Tekmen, C. (2006). The effect of $\mathrm{SiC}_{\mathrm{p}}$ reinforcement on the corrosion behaviour of $\mathrm{Al}$ based metal matrix composites. Corrosion Reviews, vol. 24, p. 27-37.

[27] Dikici, B., Bedir, F., Gavgali, M., Kiyak, T. (2009). Corrosion characteristics of $\mathrm{Al}-\mathrm{Cu} /$ B4C (T6) MMCs and their microstructure 
evaluation. Kovove Mater, vol. 47, p. 317323.

[28] Lucas, K.A., Clarke, H. (1993). Corrosion of aluminium-based metal matrix composites. Research Studies Pres Ltd.

[29] Shackelford, J.F., Alexander, W. (2001). Thermal properties of materials. Materials Science and Engineering Handbook, vol. 5. CRC press.

[30] Modi, O.P., Prasad, B.K., Dasgupta, R., Jha, A.K., Mondal, D.P. (1999). Errosioncorrosion characteristics of squeeze cast aluminium alloy/SiC composites in water and sodium chloride solutions containing sand. Mater Sci Technol, vol. 15, p. 933-938.

[31] ASTM G5, Standard reference test method for making potentiostatic and potentiodynamic anodic polarization measurements, Annual Book of ASTM Standards. ASTM International.

[32] Tekmen, C., Cocen, U. (2008). Squeeze casting of Ni coated $\mathrm{SiC}$ particle reinforced Al based composite. J Comp Mater, vol. 42, p. 1271-1279.

[33] Turnbull, A. (1992). Review of corrosion studies on aluminium metal matrix composites. Br Corros $J$, vol. 27, no. 27-35.
[34] Bhat, M.S.N., Surappa, M.K. (1991). Corrosion behaviour of silicon carbide particle reinforced 6061/Al alloy composites. J Mater Sci, vol. 26, p. 4991-4996.

[35] McIntyre, J.F., Conrad, R.K., Golledge, S.L. (1990). The effect of heat treatment on the pitting behaviour of $\mathrm{SiC}_{\mathrm{w}} / \mathrm{AA} 2124$. Corros, vol. 46, p. 902-905.

[36] Trzaskoma, P.P., McCafferty, E., Crowe, C.R. (1983). Corrosion behavior of $\mathrm{SiC} / \mathrm{Al}$ metal matrix composites. Electrochem Soc $J$, vol. 130, p. 1804-1809.

[37] Ahmed, Z., Abdul Aleem, B.J. (2002). Degradation of aluminum metal matrix composites in salt water and its control. Mater Des, vol. 23, p. 173-180.

[38] Trzaskoma, P.P. (1990). Pit morphology of aluminum alloy and silicon carbide/ aluminum alloy metal matrix composites. Corrosion, vol. 46, p. 402-409.

[39] Tait, S.W. (1994). An introduction to electrochemical corrosion testing for practicing engineers \& scientists. Pair $\mathrm{O}$ Docs Publications, Madison. 